\title{
Resiliency and subjective health assessment. Moderating role of selected psychosocial variables
}

\begin{abstract}
BACKGROUND
Resiliency is defined as a relatively permanent personality trait, which may be assigned to the category of health resources. The aim of this study was to determine conditions in which resiliency poses a significant health resource (moderation), thereby broadening knowledge of the specifics of the relationship between resiliency and subjective health assessment.
\end{abstract}

\section{PARTICIPANTS AND PROCEDURE}

The study included 142 individuals. In order to examine the level of resiliency, the Assessment Resiliency Scale (SPP-25) by N. Ogińska-Bulik and Z. Juczyński was used. Participants evaluated subjective health state by means of an analogue-visual scale. Additionally, in the research the following moderating variables were controlled: sex, objective health status, having a partner, professional activity and age. These data were obtained by personal survey.

\section{RESULTS}

The results confirmed the relationship between resiliency and subjective health assessment. Multiple regression anal- ysis revealed that sex, having a partner and professional activity are significant moderators of associations between level of resiliency and subjective health evaluation. However, statistically significant interaction effects for health status and age as a moderator were not observed.

\section{CONCLUSIONS}

Resiliency is associated with subjective health assessment among adults, and selected socio-demographic features (such as sex, having a partner, professional activity) moderate this relationship. This confirms the significant role of resiliency as a health resource and a reason to emphasize the benefits of enhancing the potential of individuals for their psychophysical wellbeing. However, the research requires replication in a more homogeneous sample.

\section{KEY WORDS}

resiliency; health assessment; psychosocial variables

ORganization - 1: Department of Psychopathology and Clinical Diagnosis, Casimir the Great University, Bydgoszcz,

Poland · 2: Department of Rehabilitation Psychology Collegium Medicum, Nicolaus Copernicus University in Torun, Poland

AUthors' CONTRibutions - A: Study design - B: Data collection - C: Statistical analysis - D: Data interpretation .

E: Manuscript preparation · F: Literature search · G: Funds collection

CORRESPONDing AUthor - Michalina Sołtys, Institute of Psychology, Department of Psychopathology

and Clinical Diagnosis, Casimir the Great University, 1 Staffa Str., 85-867 Bydgoszcz, Poland,

e-mail: michalina.soltys@ukw.edu.pl

to CITE THIS ARTICLE - Sołtys, M., \& Woźniewicz, A. (2016). Resiliency and subjective health assessment. Moderating

role of selected psychosocial variables. Health Psychology Report, 4(2). DOI: 10.5114/hpr.2016.55927

RECEIVED 13.04.2015 - REVIEWED 11.05.2015 · ACCEPTED 12.06.2015 · PUBLISHED 31.12.2015 


\section{BACKGROUND}

This study is based on the salutogenic approach and is discussed in the context of positive psychology (e.g. Antonovsky, 1987; Seligman, 2002; Seligman \& Csikszentmihalyi, 2000). The fundamental goal of positive psychology is to catalyse and change the focus of psychologists from elimination of pathology to searching for ways of building positive qualities, based on the subjective perception of reality (Seligman \& Csikszentmihalyi, 2000). Positive psychology tries to show how, why and under what conditions positive emotions, individual attributes or institutions enable people to flourish (Seligman, Steen, Park, \& Peterson, 2005). It focuses on describing the results of the potential an individual may have (e.g. better physical health), and not on the ways of forming them (Seligman, 2002). One such quality is mental resiliency, which is the subject of this article (e.g. Block \& Kremen, 1996; Borys, 2010; Nadolska \& Sęk, 2007; Ogińska-Bulik, 2011). Resiliency seen as a personal resource of an individual has recently become a frequent topic of studies. Antonovsky (1987) describes resources as all source of qualities both personal and environmental, emphasising that they play a significant role in coping mechanisms. A situation when one needs such mechanisms is without doubt chronic illness.

\section{RESILIENCY AS A HEALTH RESOURCE}

Resiliency is defined as a set of personality qualities or relatively permanent personal resource that enables flexible adjusting to everyday challenges (Kaczmarek, Sęk, \& Ziarko, 2011; Nadolska \& Sęk, 2007; Ogińska-Bulik, 2011; Ogińska-Bulik \& Juczyński, 2008). Ogińska-Bulik and Juczyński (2008) opt for such understanding of resiliency including cognitive, emotional as well as behavioural components.

Furthermore, resilience is seen as a process that helps effective adaptation to stressful situations as well as coping with unfortunate events (Borucka \& Ostaszewski, 2008; Hall, Reich, \& Zautra, 2010; Harvey \& Delfabbro, 2004; Kaczmarek et al., 2011; Masten, 2001; Ogińska-Bulik, 2011; Ogińska-Bulik \& Juczyński, 2008). It is also treated as an effect of adapting to difficult and constantly changing life conditions (Butcher-Winfree, 2009; Ogińska-Bulik \& Juczyński, 2011) or as a source of motivation (Richardson, 2002).

The term resiliency reflects the constant belief that one can successfully cope with stress. It is a disposition towards being able to interpret oneself, one's social surroundings and future in a way that ensures individual adequate functioning in various areas of life including work, interpersonal relations as well as physical and mental health (Charney, 2004; Klohnen, 1996; Mak, Ng, \& Wong, 2011; Wells, 2009).
Resiliency is a phenomenon occurring more often than it was initially expected (Bonanno, 2004; Masten, 2001). It plays a significant role in the process of overcoming both traumatic experiences as well as coping with everyday challenges in life (Block \& Kremen, 1996; Kaczmarek et al., 2011; Luthar, Cicchetti, \& Becker, 2000; Masten, 2001; Ogińska-Bulik, 2011).

The research to date has shown that it is an important resource not only among healthy individuals but also the chronically ill (Block \& Kremen, 1996; Kaczmarek et al., 2011; Kim \& Yoo, 2010; Montpetit, Bergeman, Deboeck, Tiberio, \& Boker, 2010; Ogińska-Bulik, 2011; Perfect \& Jaramillo, 2012; Steward \& Yuen, 2011). It facilitates recovery among the somatically ill (Steward \& Yuen, 2011) and it is connected with improved health, both physical and mental (Block \& Kremen, 1996; Hall et al., 2010; Mak et al., 2011; Perfect \& Jaramillo, 2012; Soltys, 2013).

Resiliency is therefore considered as an important resource in the process of dealing with difficulties connected with chronic illness. Resilient individuals may perceive illness as a challenge and perform a positive re-evaluation of the situation in which they have to deal with an illness (Kaczmarek et al., 2011; Mak et al., 2011; Nadolska \& Sęk, 2007; Ogińska-Bulik, 2011; Ogińska-Bulik \& Juczyński, 2008). With reference to this fact, people may evaluate their state of health more optimistically (e.g. Kowalik, 2001). As shown by Ogińska-Bulik (2011) the ability to deal with and tolerate negative emotions as one of the subdimensions of resiliency is a crucial factor enabling patients suffering from breast cancer to adapt to illness. Furthermore, mental resiliency may, through strategies for coping with stress (e.g. positive belief concerning recovery, humour, planning or acceptance) increase the satisfaction of life as well as reducing the feeling of hopelessness and helplessness in various groups of patients (cardiological, with diabetes or rheumatoid arthritis) (Kaczmarek et al., 2011). As a result, the positive affect that directly influences the immune system may have a positive impact on one's health. The condition of the immune system in turn may determine affect and indirectly the ability to use psychological and social resources, as well as motivation to health-building behaviours (Salovey et al., 2000). In fact, research results show that wildly optimistic beliefs about the future may protect against development of the illness. Optimistic patients are more eager to benefit from social support or to cultivate health-improving habits (Taylor, Kemeny, Reed, Bower, \& Gruenewald, 2000). Another study, on the other hand, showed that health state does not differentiate women on account of their level of resiliency (Soltys, 2013). It would suggest that the objective health state plays a secondary role, while the way we perceive our health depends mostly on our resources (e.g. Kowalik, 2001; Ryff \& Sing- 
er, 2002). Results concerning the association between resiliency and subjective as well as objective health state are not conclusive. Therefore extended research on the relation between mental and physical health seems to be necessary (e.g. Ryff \& Singer, 2002).

\section{MODIFYING FACTORS OF THE ASSOCIATIONS BETWEEN RESILIENCY AND THE HEALTH ASSESSMENT AND THE HEALTH STATE}

In most of the research publicized so far, the demographic variables are controlled and the differences between groups in this matter are reduced as much as possible. Much less common is considering socio-demographic variables as important factors that modify relations between the variables. That is why we decided to determine the role of particular psychosocial variables in forming the relation between resiliency and subjective health assessment.

Research results concerning differences between the way of forming resiliency among men and women are not conclusive (Block \& Kremen, 1996; Chuang, Lamb, \& Hwang, 2006; Manicavasagar, 2008; Perfect \& Jaramillo, 2012). According to the results of research conducted by Block and Kremen (1996) young resilient women show lower ego control and a higher sense of autonomy. Men show a tendency to intensified ego-control and establishing friendly relationships. It proves that the way of manifesting resiliency differs in these groups. Nonetheless, the participants in both groups did not fall into stereotypical gender roles. On the other hand, according to Manicavasagar (2008) resiliency among girls is formed by building friendly relationships and in the case of boys by solving problems. Resiliency seems to be more stable in the time of adolescence among men, but girls show a higher level of resiliency than boys in this period, which additionally increases with age (Chuang et al., 2006). In research conducted by Perffect and Jaramillo (2012) there was no statistically significant correlation between sex and resiliency.

There is also little coverage about the relations between marital status and resiliency (Sołtys, 2013; Wade, Hart, Wade, Bajaj, \& Price, 2013; Wells, 2009). Part of the research shows a lack of correlation between marital status and the level of resiliency (Soltys, 2013; Wells, 2009), while other research suggests that widows are characterized by higher resiliency than divorcees, married women as well as those in separation. Although in this research a direct measurement of resiliency has not been made, the level of resiliency was estimated based on emotionality and a questionnaire for measuring pain (Wade et al., 2013).

So far rare studies show a lack of associations between resiliency, employment and income, whereas the relationship between being employed and health assessment is more profound. Numerous studies have confirmed that employed individuals enjoy better health and more quickly return to a condition typical for them after illness (Bartley, Sacker, \& Clarke, 2004; Wells, 2009; Sołtys 2013).

Moreover, research conducted by Ogińska-Bulik and Juczyński $(2008,2011)$ showed that older people are characterised by a higher level of resiliency in all aspects of resiliency apart from openness to new experiences and sense of humour. Openness to new experience and sense of humour as well as tolerance of failures and treating life as a challenge correlate positively with the subjective assessment of health (Soltys, 2013). Some of the results show, however, that there is no correlation between age and resiliency (Wells, 2009).

The aim of this study was to determine the conditions (role of selected psychosocial variables) in which resiliency is a significant health resource (moderation), thereby broadening knowledge on specifics of the relation between resiliency seen as a personality trait and a subjective health assessment.

Moderation should be understood as interaction between a particular variable (called a "moderator") and an independent variable. A moderator influences therefore the way the independent variable interacts with the dependent variable. Interaction of a predicator and a dichotomous moderator is based on the principle that the connection between the independent and dependent variable takes a different sign $(-/+)$ and/or direction in the subgroups depending on the character of the moderator. In other words, moderation enables us to determine the specifics of an occurring relation (Bedyńska, 2012).

\section{PARTICIPANTS AND PROCEDURE}

In the study there participated 142 individuals aged $18-78(M=38.65, S D=13.60)$. We examined 76 men and 66 women. Men significantly differed from women regarding average age $(t=-3.72, d f=140, p=.001)$. Average age in the male group was $34.86(S D=10.96)$, whereas in the female group it was $43.02(S D=15.05)$. Fifty-nine participants were chronically ill, while 83 were in good health.

Chronically ill participants significantly differed from those remained healthy regarding their age $(z=-5.80, p<.001)$. Healthy individuals turned out to be significantly younger $(M=32.60, S D=8.63)$ than the chronically ill $(M=47.15, S D=14.79)$.

Detailed data regarding types of chronic diseases from which the participants suffered are presented in Figure 1.

A group of 109 participants were employed, whereas 31 remained unemployed. Two participants did not state their professional activity. Regarding personal life, 93 people reported having a partner (83 people were married, 10 people had partners but
Resiliency and subjective health assessment 
Michalina Sołtys, Agnieszka Woźniewicz

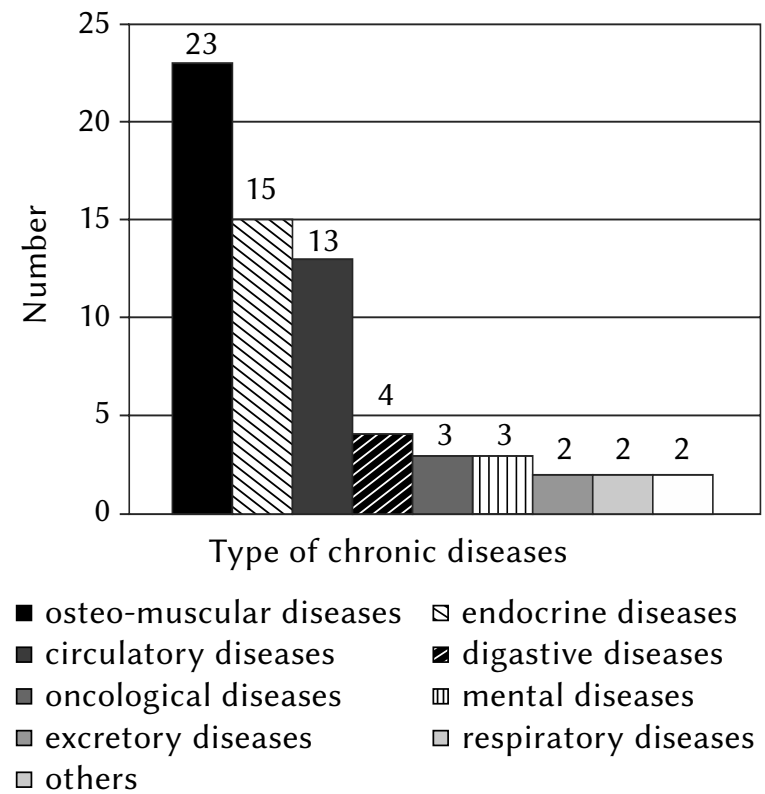

Figure 1. Chronic diseases in research sample.

remained unmarried). Forty-nine people did not have a partner (45 were unmarried, 4 divorced).

A series of analyses using Pearson's $\chi^{2}$ test showed that among healthy and chronically ill participants, there is a statistically significant difference in distribution regarding such factors as sex $\left(\chi^{2}=32.34\right.$, $p<.001)$, having a partner $\left(\chi^{2}=4.08, p=.043\right)$ and professional activity $\left(\chi^{2}=22.22, p=.001\right)$. The group of healthy individuals consisted mostly of men $(n=71)$, while most persons in the group of chronically ill were women $(n=34)$. Additionally, most of the healthy participants had a partner $(n=60)$, whereas among the chronically ill 26 were single and 33 respondents were married or in a non-marital relationship. As for employment, in the group of healthy persons, 7 of them were unemployed, whereas in the group with chronic illness 24 participants were not professionally active.

In this study resiliency was measured by OgińskaBulik and Juczyński's (2008) the Assessment Resiliency Scale. It consists of 25 statements to which the participants take a stance using a 5-point Likert scale. Cronbach's $\alpha$ reliability coefficient for the general result obtained by the authors of the scale was .89 , whereas for individual factors it varied from .67 to .75 . Test-retest stability measured after 4 weeks was .87 .

Subjective health assessment was measured by the analogue-visual scale (thermometer). The respondents were asked to mark with a line of $100 \mathrm{~mm}$ to what extent they feel healthy, where the start of the line represented "I feel completely ill" and the end represented "I feel fully healthy".

The researchers gained information on age, sex, marital status, education, professional activity, health state and the type and duration of chronic disease by using a personal survey.
The statistical analysis was conducted with STATISTICA version 10. Descriptive statistics, Pearson's $r$ correlation, multiple regression analyses and difference tests were used.

The following research questions were posed:

1. Is there an association between resiliency and the subjective health assessment?

2. Does sex moderate the relationship between resiliency and the subjective health assessment?

3. Does health state (disease/lack of disease) moderate the relationship between resiliency and the subjective health assessment?

4. Does having a partner moderate the relationship between resiliency and the subjective health assessment?

5. Does professional activity moderate the relationship between resiliency and the subjective health assessment?

6. Does age moderate the relationship between resiliency and the subjective health assessment?

\section{RESULTS}

First we conducted data analyses at the level of descriptive statistics. The analyses were performed in order to test whether observed relations between variables may be interpreted as random error or are a consequence of systematically occurring association and differences. As sampling was purposive, we cannot directly conclude that the obtained results are true for the general population. Analyses with the Kolmogorov-Smirnov test showed that the distribution for the resiliency variable (general result) and age does not significantly differ from normal distribution. Distribution of the subjective health assessment deviates significantly from normal distribution, though the value of kurtosis (-.17) and skewness (-.81) enable us to assume that the observed deviation is not dramatically high. Results for particular subscales of resiliency did not show a normal distribution. Despite differences from the normal distribution mentioned above, we used the central limit theorem, which states that in big samples the distribution of average values resembles the normal distribution. Because of that, in part of the analyses we used parametric tests.

In order to examine whether there is a significant correlation between resiliency and subjective health assessment (thereby whether searching for moderators of this association is justified) Pearson correlation analysis was used. The results are presented in Table 1.

It was found that resiliency (and its contributing factors) correlates significantly at a low or medium level with subjective health assessment. The obtained results enable us to answer the first posed research question in the affirmative.

Due to the results, the next step was to find moderators of the relationship between resiliency (its 
Table 1

Relationship between resiliency, its contributing factors and the subjective health assessment $(N=142)$

\begin{tabular}{lc}
\hline Variables & Subjective health assessment \\
\hline Persistence and determination & $.22^{* *}$ \\
Openness to new experiences and a sense of humour & $.38^{* * *}$ \\
Ability to cope and tolerate negative emotions & $.39^{* * *}$ \\
Ability to tolerate failures and view life as a challenge & $.37^{* * *}$ \\
Optimism in life and ability to focus in adversity & $.29^{* * *}$ \\
Resiliency - summed score & $.38^{* * *}$ \\
\hline Note. ${ }^{* *} p<.01 ;{ }^{* * *} p<.001$ &
\end{tabular}

Resiliency and subjective health assessment general results) and the subjective health assessment. Hence, a multiple regression analysis was performed, prior to which we centred the variables (by subtracting the mean from the result obtained for the quantities variable) as well as creating appropriate interaction factors for them. Firstly, the moderating role of sex was tested. Results of the multiple regression analysis with interaction are presented in Table 2 . This model turned out to be statistically significant $(F(3,136)=24.14, p<.001)$. In total, it explains $34.70 \%$ of the variance for the subjective health assessment variable. More importantly, it showed that sex is a significant moderator of the studied relationship.

Resiliency predicts the subjective health assessment only in the male group $(F(1,74)=62.99$, $\left.p<.001, R^{2}=.46, B=.68, t=7.94, p<.001\right)$. The higher the level of resiliency, the more positively respondents evaluate their health. In the female group the same effect was not observed. Furthermore, women presented a significantly lower level of subjective health assessment $(M=64.81, S D=22.01$ vs. $M=84.04$, $S D=15.01, z=5.35, p<.001)$ and resiliency $(M=72.79$, $S D=12.88$ vs. $M=78.20, S D=11.69, z=2.77, p=.006)$ than men. However, it should be noted that women in the research sample were significantly older than men, which may partly explain the obtained results. Average age of men was $34.86(S D=10.96)$, while in the group of women it was $43.02(S D=15.05)$.

The second aspect taken into consideration was whether health status moderates the relationship between resiliency and the subjective health assessment. Regression analysis did not reveal a significant interaction effect $(B=.01, p=.863)$. Nevertheless, the model without the interactional component shows a good fit to the data $(F(2,137)=56.07, p<.001)$ and it predicts $45 \%$ of variance for subjective health assessment. Resiliency and objective health status are two independent predictors of health assessment. Resiliency moderately predicts better health status in the healthy group $(B=.47, p<.001)$, whereas in the group of chronically ill participants the level of prediction is lower $(B=.30, p=.020)$ (Table 3$)$.

Interestingly, it was found that whereas healthy and ill participants significantly differ from each other in range of subjective health assessment $(M=85.43$, $S D=12.99$, vs. $M=60.58, S D=21.38, z=6.75$, $p<.001)$, such statistically significant difference were not observed for the level of resiliency $(M=77.16$,

Table 2

Moderating role of sex - results from multiple regression analysis with interaction in second step

\begin{tabular}{lccccc}
\hline Predictors & $B$ & $S E$ & $t$ & $p$ & $R^{2}$ \\
\hline Sex & -.40 & .07 & -5.66 & $<.001$ & .30 \\
Resiliency & .31 & .07 & 4.30 & $<.001$ & .003 \\
Interaction & -.21 & .07 & -3.01 & .35 \\
\hline
\end{tabular}

Table 3

Moderating role of health status - results from multiple regression analysis with interaction in second step

\begin{tabular}{lccccc}
\hline Predictors & $B$ & $S E$ & $t$ & $p$ & $R^{2}$ \\
\hline Health status & -.55 & .06 & -8.55 & $<.001$ & .45 \\
Resiliency & .31 & .07 & 4.84 & $<.001$ & .863 \\
Interaction & .01 & .06 & 0.17 & .45 \\
\hline
\end{tabular}


Michalina Sołtys, Agnieszka Woźniewicz
$S D=12.05$ vs. $M=73.61, S D=12.93, z=1.81, p=.070)$ To sum up, health status does not play a moderating role between resiliency and subjective health evaluation.

Fourthly, we tested whether being in a relationship, both marital and non-marital, modifies the relation between resiliency and subjective health assessment. Multiple regression analysis (Table 4) confirmed that interaction. However, the model explains only $20 \%$ of variance for subjective health assessment. It was observed that the having a partner variable separately does not predict subjective health assessment, but allows one to predict it in the interaction with resiliency. In the group of participants who were single, a relationship between resiliency and subjective health evaluation was not revealed ( $B=.03, p=.823)$, whereas a strong positive correlation was noted among respondents who had a part$\operatorname{ner}(F(1,91)=37.75, B=.54, p<.001)$.

Afterward, it was tested whether professional activity (being employed/unemployed) plays a role as a moderator between resiliency and subjective health assessment. Results of the performed analysis are presented in Table 5.

Further analyses using the Mann-Whitney $U$ test showed that unlike the unemployed, working individuals exhibit a significantly higher level of resiliency $(M=79.96, S D=10.86$ vs. $M=67.58, S D=14.62$, $z=3.64, p=.001)$ and a better assessment of their health status $(M=79.77, S D=18.20$ vs. $M=58.74$, $S D=22.15, z=4.46, p=.001)$.

Lastly, we verified whether age plays a moderating role between resiliency and the subjective assessment of health. Results of the analysis are presented in Table 6.

Multiple regression analysis revealed that the model with the interaction factor shows a good fit to the data $(F(3,138)=28.06, p<.001)$. Nevertheless, the model with two predictors is equally well fitted as the first model and it explains $36.90 \%$ of the variance for subjective health assessment. The interaction effect, on the other hand, was found not to be significant. This suggests that age does not play a role of a moderator in the tested relationship and independently from resiliency predicts a poorer assessment of one's health.

\section{DISCUSSION}

The aim of this study was to determine the role of psychosocial variables in modifying the relation between resiliency, seen as a health resource, and the subjective assessment of health performed by the participants.

The obtained research results confirm that resiliency as a personality trait is a significant, yet moder-

Table 4

Moderating role of having a partner - results from multiple regression analysis with interaction in second step

\begin{tabular}{lccccc}
\hline Predictors & $B$ & $S E$ & $t$ & $p$ & $R^{2}$ \\
\hline Having a partner & .02 & .08 & 0.21 & .837 & .15 \\
Resiliency & .30 & .09 & 3.48 & $<.001$ & .010 \\
Interaction & .22 & .09 & 2.63 & .20 \\
\hline
\end{tabular}

Table 5

Moderating role of professional activity - results from multiple regression analysis with interaction in second step

\begin{tabular}{lccccc}
\hline Predictors & $B$ & $S E$ & $t$ & $p$ & $R^{2}$ \\
\hline Employment & .38 & .08 & 4.57 & $<.001$ & .24 \\
Resiliency & .22 & .08 & 2.68 & .008 & .033 \\
Interaction & .17 & .08 & 2.16 & .27 \\
\hline
\end{tabular}

Table 6

Moderating role of age - results from multiple regression analysis with interaction in second step

\begin{tabular}{lccccc}
\hline Predictors & $B$ & $S E$ & $t$ & $p$ & $R^{2}$ \\
\hline Age & -.49 & .07 & -7.12 & $<.001$ & .37 \\
Resiliency & .32 & .07 & 4.75 & $<.001$ & .922 \\
Interaction & .01 & .07 & 0.10 & .37 \\
\hline
\end{tabular}


ately strong resource of health. Meanwhile one's sex, having a partner and professional activity moderate the relationship between resiliency and subjective health evaluation. Against the predictions, health status and age were not found to be mediators in the tested relation.

The findings enable us to conclude that subjective perception of health in contrast to objective health status (understood as suffering or not from a somatic disease) is a more reliable indicator of resiliency. More important seems to be how individuals perceive their health. This fact accentuates the role of health resources (e.g. Kowalik, 2001; Ryff \& Singer, 2002).

According to Klohnen (1996), resilient individuals who experience difficulties could concentrate more on the most important aspects of the situation. They see stressful events as a challenge and failures are perceived as a natural element of life (Semmer, 2006). Additionally, they present a sense of humour and a positive attitude toward life (Klohnen, 1996; Ogińska-Bulik \& Juczyński, 2008).

Nadolska and Sęk (2007) emphasize that individuals with a high resiliency level are able to modify their own schemata and use accommodated knowledge to function more effectively in changing and stressful conditions. They can re-evaluate the meaning of extreme experiences (somatic disease may be one of such events) and include them in the story of their lives (Ogińska-Bulik \& Juczyński, 2008; Manicavasagar, 2018; Ogińska-Bulik, 2011). These arguments may explain the lack of interaction between health status and resiliency as well as the lack of differences in the levels of resiliency among healthy and chronically ill participants.

Results pertaining to the moderating role of age are self-explanatory. Loss of fitness is a natural consequence of aging, which is reflected in the evaluation of one's health. Nonetheless, age does not differentiate the relationship between resiliency and the subjective sense of health, whereas resiliency as a personality trait seems to be a permanent feature, influencing the individual in all aspects of his or her life. Nevertheless, in order to state with certainty that resiliency is, in fact, a constant trait and describe the character of occurring relations, there is a need to conduct either cohort or longitudinal studies.

It is also interesting that resiliency seems to be a health resource only in the male group. The results should be treated with caution though, considering the fact that the female group was significantly older than the male one. Probably we are dealing with a spurious relationship, which is caused by a negative correlation between resiliency and age. Additionally, most men did not suffer from any chronic disease. It is also possible that because of gender stereotypes, men show fewer tendencies to present their everyday difficulties and struggles compared to women (e.g. Block \& Kremen, 1996).
The moderating role of having a partner turned out to be quite weak, yet significant, whereas the fact of having a partner does not, according to our results, predict better health. Nevertheless, the positive correlation between resiliency and the sense of health in the group of participants in marital or cohabitational relationships was definitely confirmed. The obtained results contradict previously published studies on resiliency (e.g. Sołtys, 2013; Wade et al., 2013; Wells, 2009), but they are consistent with numerous studies on the role of marital status conducting in the field of positive psychology. The presented disparity may derive from different methods of variable operationalisation. In future studies the sample should be selected more precisely in order to analyse separately results from respondents in marital and non-marital relationships as well as those who remain single, widowed or divorced. It may well be that the results of all research conducted on this matter (the role of having a partner) are in fact the effect of social support, provided by loved ones. That is why this variable should be taken into consideration in future studies.

The results concerning the moderating role of professional activity were not surprising. They tend to claim that being employed is a better predictor of health assessment than resiliency. The most probable explanation of this interaction effect is that resilient individuals are better at adapting to life conditions and hence they may experience fewer difficulties in looking for employment and in young or late adulthood they remain active, which helps them to maintain physical health.

The conducted research has some limitations. The most serious of them are the disproportions of distribution in various groups, as well as a non-representative and non-homogeneous sample, especially in the case of chronically ill individuals. That is why we treat the obtained results as a starting point and as encouragement for further studies on the modifying role of selected psychosocial variables in the context of resiliency and subjective health assessment.

\section{CONCLUSIONS}

Resiliency is connected with subjective health assessment in adults, and demographic features modify this relation. It confirms the significant role of resiliency as a health resource, crucial for maintaining health. It also enables us to emphasize the benefits of enhancing the potential of individuals in order to care about their psychophysical wellbeing.

\section{RefERENCES}

Antonovsky, A. (1987). Unravelling the mystery of health: How people manage stress and stay well. San Francisco: Jossey-Bass Publishers.
Resiliency and subjective health assessment 
Bartley, M., Sacker, A., \& Clarke, P. (2004). Employment status, employment conditions, and limiting illness: prospective evidence from the British household panel survey 1991-2001. Journal of Epidemiology and Community Health, 58, 501-506.

Bedyńska, M. (2012). Statystyczny drogowskaz 3 [Statistical signpost 3]. Warszawa: Wydawnictwo Akademickie Sedno.

Block, J., \& Kremen, A. M. (1996). IQ and ego-resiliency: Conceptual and empirical connections and
Michalina Sołtys, Agnieszka Woźniewicz separateness. Journal of Personality and Social Psychology, 70, 349-361.

Bonanno, G. A. (2004). Loss, trauma, and human resilience: Have we underestimated the human capacity to thrive after extremely adverse events? American Psychologist, 59, 20-28. DOI: 10.1037/0003-066X.59.1.20

Borucka, A., \& Ostaszewski, K. (2008). Koncepcja resilience. Kluczowe pojęcia i wybrane zagadnienia [The concept of resilience. Key notions and selected issues]. Medycyna Wieku Rozwojowego, 12, 587-597.

Borys, B. (2010). Zasoby zdrowotne w psychice człowieka [Health resources in the human psyche]. Forum Medycyny Rodzinnej, 4, 44-52.

Butcher-Winfree, J. A. (2009). Portraits of resiliency: A qualitative study of Appalachian Christian women (Doctoral dissertation). Retrieved from Marshall Digital Scholar.

Charney, D. S. (2004). Psychobiological mechanisms of resilience and vulnerability: Implications for successful adaptation to extreme stress. American Journal of Psychiatry, 161, 195-216.

Chuang, S., Lamb, M., \& Hwang, C. (2006). Personality development from childhood to adolescence: A Longitudinal study of ego-control and ego-resiliency in Sweden. International Journal of Behavioral Development, 30, 338-343.

Hall, J. S., Reich, J. W., \& Zautra, A. J. (2010). Handbook of adult resilience. New York: The Guilford Press.

Harvey, J., \& Delfabbro, H. (2004). Psychological resilience in disadvantaged youth: A critical review. Australian Psychologist, 39, 3-13.

Kaczmarek, Ł., Sęk, H., \& Ziarko, M. (2011). Resiliency and the mediators if its effect on health. The Review of Psychology, 54, 29-46.

Kim, D. H., \& Yoo, I. Y. (2010). Factors associated with resilience of school age children with cancer. Journal of Paediatrics and Child Health, 46, 431-436. DOI: 10.1111/j.1440-1754.2010.01749.x

Klohnen, E. C. (1996). Conceptual analysis and measurement of the construct of ego-resiliency. Journal of Personality and Social Psychology, 70, 10671079. DOI: 10.1037/0022-3514.70.5.1067

Kowalik, S. (2001). Użyteczność koncepcji jakości życia dla procesu rehabilitacji osób niepełnosprawnych [The usefulness of the concept of qual- ity of life for the process of rehabilitation of people with disabilities]. In: L. Wołowicka (ed.), Jakość życia w naukach medycznych [The quality of life in medical sciences] (pp. 54-77). Poznań: UM.

Luthar, S., Cicchetti, D., \& Becker, B. (2000). The construct of resilience: Critical evaluation and guidelines for future work. Child Development, 71 , 543-562.

Mak, W. W., Ng, I. S., \& Wong, C. C. (2011). Resilience: Enhancing well-being through the positive cognitive triad. Journal of Counseling Psychology, $58,610-617$.

Manicavasagar, V. (2008). Psychological resilience. Ezine Articles. Retrieved from: http://ezinearticles. com/?Psychological-Resilience \&id $=1688230$

Manicavasagar, V. (2008). Psychological resilience. Ezine Articles. Retrieved from: http://ezinearticles.com/?Psychological-Resilience $\& i d=1688230$ [2012, August 20].

Masten, A. S. (2001). Resilience processes in development. American Psychologist, 56, 227-238.

Montpetit, M. A., Bergeman, C. S., Deboeck, P. R., Tiberio, S. S., \& Boker, S. M. (2010). Resilience-as-process: Negative affect stress and coupled dynamical systems. Psychology and Aging, 25, 631-640.

Nadolska, K., \& Sęk, H. (2007). Społeczny kontekst odkrywania wiedzy o zasobach odpornościowych, czyli czym jest resilience i jak ono funkcjonuje [The social context of discovering immunity resources. What is resilience and how it works]. In: Ł. Kaczmarek \& A. Słysz (eds.), Bliżej serca - zdrowie i emocje [Closer to heart. Health and emotions] (pp. 13-37). Poznań: UAM.

Ogińska-Bulik, N. (2011). Rola prężności psychicznej w przystosowaniu się kobiet do choroby nowotworowej [The role of resiliency in adjustment to cancer among women]. Psychoonkologia, 1, 16-24.

Ogińska-Bulik, N., \& Juczyński, Z. (2011). Resiliency in children and adolescents: characteristics and measurement - Polish Scale SPP-18. Polskie Forum Psychologiczne, 16, 7-28.

Ogińska-Bulik, N., \& Juczyński, Z. (2008). Skala pomiaru prężności - SPP-25 [Polish Resiliency Measurement Scale - SPP-25]. Nowiny Psychologiczne, 3, 39-56.

Perfect, M. M., \& Jaramillo, E. (2012). Relations between resiliency, diabetes-related quality of life, and disease markers to school-related outcomes in adolescents with diabetes. School Psychology Quarterly: The Official Journal of the Division of School Psychology, American Psychological Association, 27, 29-40. DOI: 10.1037/a0027984

Richardson, G. E. (2002). The metatheory of resilience and resiliency. Journal of Clinical Psychology, 58, 307-321.

Ryff, C. D., \& Singer, B. (2002). Ironies of the human condition: Well-Being and health on the way to 
mortality. In: L. G. Aspinwall \& U. M. Staudinger (eds.), A psychology of Human strengths: Fundamental questions and future directions for a positive psychology (pp. 271-287). Washington, PC: American Psychological Associations.

Salovey, P., Rothman, A. J., Detweiler, J. B., \& Steward, W. T. (2000). Emotional states and physical health. American Psychologist, 55, 110-121. DOI: 10A037//0003-O66X.55.1.110

Seligman, M. E. P. (2002). Authentic happiness: Using the new positive psychology to realize your potential for lasting fulfillment. New York: Free Press.

Seligman, M. E. P., Steen, T., Park, N., \& Peterson, Ch. (2005). Positive psychology progress: Empirical validation of interventions. American Psychologist, 60, 410-421.

Semmer, N. (2006). Personality, stress and coping. In: M. Vollrath (ed.), Handbook of Personality and Health (pp. 73-113). Chichester: Wiley.

Sołtys, M. (2013). Prężność i orientacje religijne jako wyznaczniki postaw życiowych kobiet [Resiliency and religious orientation as indicators of women's life attitudes (Unpublished master's thesis)]. Casimir the Great University, Bydgoszcz.

Steward, D. E., \& Yuen, T. A. (2011). A systematic review of resiliency in the physically ill. Psychosomatics, 52, 199-209.

Taylor, S. E., Kemeny, M. E., Reed, G. M., Bower, J. E., \& Gruenewald, T. L. (2000). Psychological resources, positive illusions, and health. American Psychologist, 55, 99-109.

Wade, J. B., Hart, R. P., Wade, J. H., Bajaj, J. S., \& Price, D. D. (2013). The relationship between marital status and psychological resilience in chronic pain. Pain Research and Treatment, 2013, 928473. DOI: 10.1155/2013/928473

Wells, M. (2009). Resilience in rural community-dwelling older adults. The Journal of Rural Health, 25, 415-419. 